\title{
Secondary Flow Phenomena in Rotating Radial Straight Pipes
}

\author{
K. C. CHENG and LIQIU WANG \\ Department of Mechanical Engineering, University of Alberta, Edmonton, Alberta, Canada T6G 2G8
}

\begin{abstract}
Flow visualization results for secondary flow phenomena near the exit of a rotating radial-axis straight pipe (length $\ell=82$ $\mathrm{cm}$, inside diameter $\mathrm{d}=3.81 \mathrm{~cm}, \ell / \mathrm{d}=21.52$ ) are presented to study the stabilizing (relaminarization) and destabilizing (early transition from laminar to turbulent flow) effects of Coriolis forces for Reynolds numbers $\operatorname{Re}=500 \sim 4,500$ and rotating speeds $n=0 \sim 200 \mathrm{rpm}$. The flow visualization was realised by smoke injection method. The main features of the transition phenomena are disclosed for $\mathrm{Re}=1,500$ and 4,500. The observed secondary flow patterns are found to be quite different from those obtained by theoretical or numerical analysis with one pair of symmetric and steady counter-rotating vortices. The practical implications of the visualization study are pointed out.
\end{abstract}

Key Words: Rotating radial pipes; Visualization; Transition flow

\section{INTRODUCTION}

$\mathbf{F}$ low phenomena in rotating coolant channels are of practical importance in such applications as coolings of gas turbine rotor blades, rotors of electric machinery, and many other rotating components of rotating machinery.

Consideration is given here to the problem of the laminar or turbulent flow through a circular straight pipe constrained to rotate about an axis perpendicular to its central axis at a constant angular velocity. The fluid is then subject to the action of a Coriolis force in addition to the pressure gradient. The Coriolis forces in the cross-sectional plane set up secondary flow and thus modify the axial velocity profile. The case of fully developed laminar flow with small rotational speeds was solved by Barua [1954] and Benton [1956] using a small perturbation expansion method. Other theoretical and numerical studies were carried out by the following investigators: Benton and Boyer [1966]; Mori and Nakayama [1968]; Duck [1983]; Berman and Mockros [1984]; Mansour [1985]; Ito et al. [1986]; Lei and Hsu [1990]; and Ishigaki and Tamura [1991]; Ishigaki [1994].
Experimental studies were carried out by Trefethen [1957], Ito and Nanbu [1971] and Mori et al. [1971].

It is generally understood that secondary flow phenomena in curved pipes, heated or cooled horizontal pipes, and rotating radial straight pipes caused by centrifugal, buoyancy, and Coriolis forces, respectively, are somewhat analogous and are characterized by a pair of counter-rotating vortices across the cross-section normal to the main flow. In the past flow in curved pipes has been studied most extensively. In contrast, flow in rotating radial straight pipes has received less attention in the past.

As Reynolds number increases from lower to higher values, one expects the secondary flow patterns caused by body forces to change and the symmetry and steady flow field cannot be maintained. The physical model for theoretical analysis usually assumes that a pair of counter-rotating vortices persists even at higher Reynolds numbers. Apparently, the theoretical model for higher Reynolds numbers has not been confirmed by flow visualization study. It is thus clear that the understanding of secondary flow phenomena (structure, instability and transition) is basic to the analysis of flow and forced convection heat transfer problems. 
Recently Cheng and Wang [1993] presented flow visualization studies on the stabilizing and destabilizing effects of Coriolis forces in rotating radial straight pipes for Reynolds numbers $\mathrm{Re}=500,2000,3000$ and 4000 and rotating speeds $n=24 \sim 350 \mathrm{rpm}$. The purpose of this paper is to present further flow visualization results as revealed by a smoke injection method for secondary flow phenomena depicting instability, transition to turbulence and relaminarization for Reynolds numbers $\mathrm{Re}=$ 1500 and 4500 and rotating speeds $n=25 \sim 200 \mathrm{rpm}$. The secondary flow patterns are also shown for the stationary case for a range of Reynolds numbers $\mathrm{Re}=$ $500 \sim 4500$ for reference. At present flow visualization results for secondary flow phenomena in rotating radial channels are rather limited and experimental results are mainly concerned with friction factor and heat transfer results.

\section{EXPERIMENTAL APPARATUS AND FLOW VISUALIZATION METHOD}

A schematic diagram of the experimental apparatus is shown in Fig. 1. The experimental apparatus consists of a rotating test section (see Fig. 2), an air supply system including pressure regulator and air tank, a laminar flow element, a smoke generator and rotating seal. The building compressed air was used.

The rotating test section installed on the turning table consists of a plenum box $(15.24 \mathrm{~cm}$ cube), a smooth contraction from $15 \mathrm{~cm}$ dia. to $3.81 \mathrm{~cm}$ dia. over the length of $12 \mathrm{~cm}$, and a Plexiglas test tube (dia. $\mathrm{d}=3.81$ $\mathrm{cm}$, length $\ell=82 \mathrm{~cm}$ ). The plenum box and contraction section were designed to obtain an approximately uni- form entrance velocity to the test section. The air flows through a rotating vertical straight (inside diameter $=4$ $\mathrm{cm}$ ) along the axis of rotation (see Fig. 1) and then enters the plenum box and contraction section before entering the test section. The top view of the test section is shown in Fig. 2. The whole test section is transparent

The rotating table is driven by an electric motor with adjustable speed drive and the range of rotating speeds can be $\mathrm{n}=0 \sim 500 \mathrm{rpm}$. The rotational speed is measured by using an optical slot switch running on a disc with 60 equally spaced holes near its perimeter. The signal from the switch is fed to a Hewlett Packard HP5314A universal counter. With 60 holes in the disc, the frequency in $\mathrm{Hz}$ equals the rotational speed in $\mathrm{rpm}$.

A second disc with a single hole provides a signal for firing the General Radio 1540 Strobolume by way of a delay generator/single flash flip-flop which allows visual observation using a slit light source with one flash per revolution and also permits a single, properly timed flash for photographing the whole flow field. The duration of the flash is $15 \mu \mathrm{s}$.

The air flow rate was measured by a Meriam laminar flow element with a calibrated differential pressure transducer. The smoke generated by burning Chinese incense sticks was injected through a dispersing tube before the test section as shown in Fig. 1. Notice the relative location of smoke injection. The smoke particles following the flow were instantly photographed at a cross-section $10 \mathrm{~mm}$ upstream of the exit of the test section, revealing the secondary flow patterns. The light sheet through the transparent tube was about $2 \mathrm{~mm}$ (thickness). A Nikon FM2 single lens reflex camera with $55 \mathrm{~mm}$ micro-lens and Kodak T Max black and white film P3200 were used.

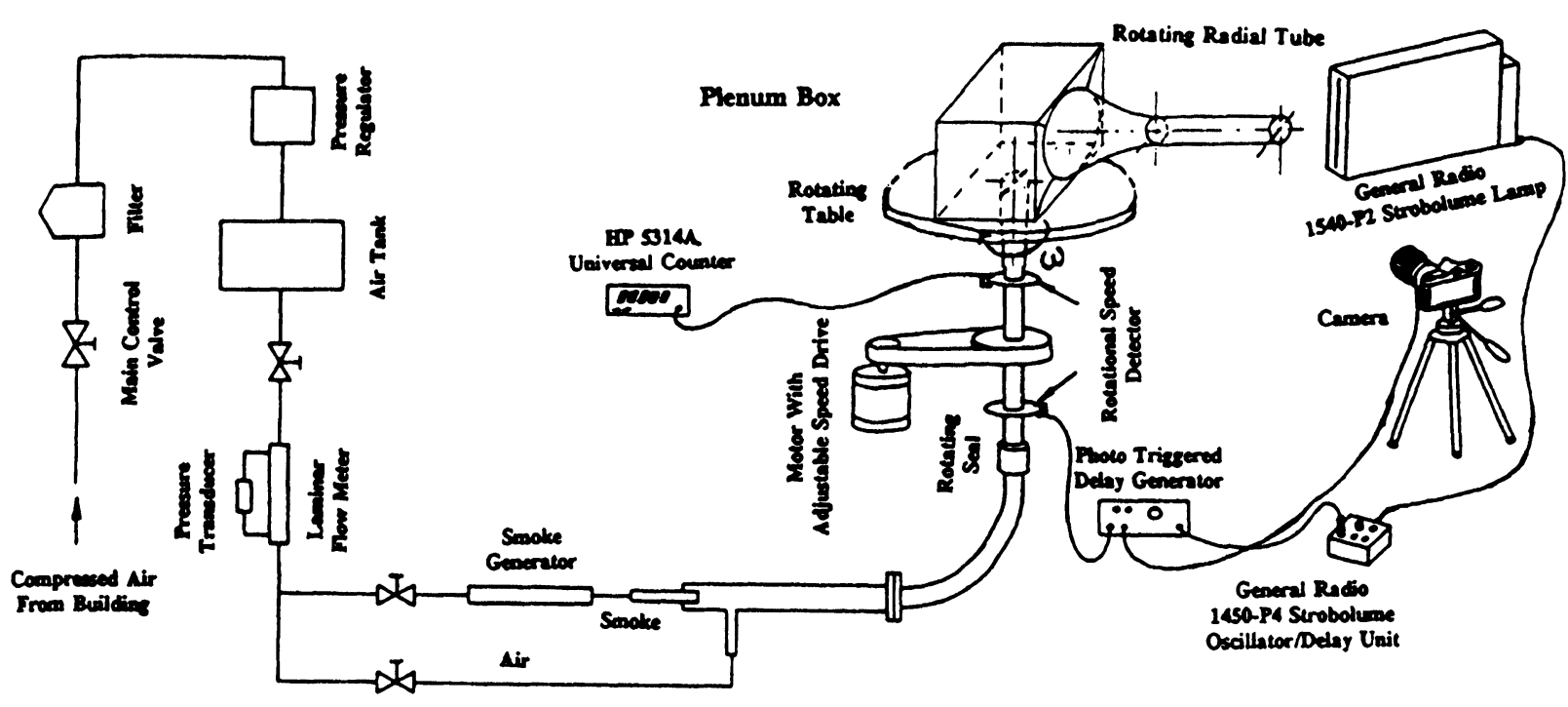

FIGURE 1 Schematic diagram of experimental apparatus. 


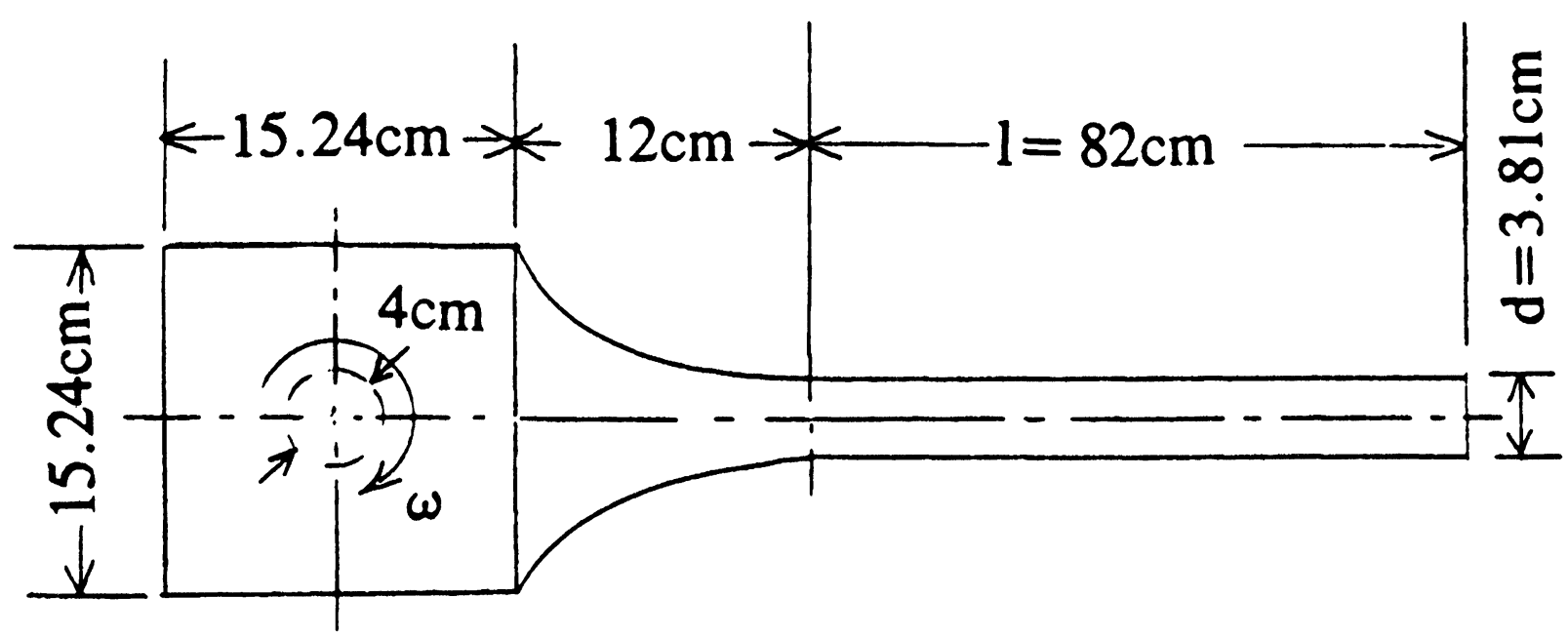

FIGURE 2 Top view of rotating test section for radial-axis straight pipe.

\section{EXPERIMENTAL PARAMETERS}

The experimental parameters for the present investigation are: rotating straight tube length-diameter ratio $(\ell / d)$, Reynolds number $R e$, rotational Reynolds number $\operatorname{Re}_{\omega}$, rotation number Ro and rotating speed $\mathrm{n}$. The parametric values are listed in Table 1.

It is noted that in the literature the rotation Reynolds number $\left(\operatorname{Re}_{\omega}\right)$ is also known as Taylor number or reciprocal of Ekman number and the rotation number represents the reciprocal of Rossby number. The present parameters are used for easy understanding of rotation effect with the limiting case as $\omega \rightarrow 0(\mathrm{n} \rightarrow 0)$.

Apparently the entrance length data (experimental or theoretical) for rotating radial straight tube with uniform entry flow are not available in the literature. Using the entrance length equation $\ell / d=0.05 \mathrm{Re}$ for laminar flow $(\operatorname{Re}<2300)$ in straight tube as an estimate, it is found that with the tube length-diameter ratio $\ell / d=21.52$, the laminar flow at the exit of the rotating straight tube should be regarded as developing flow. For turbulent entry flow $(\operatorname{Re}>2300)$, the entry length for rotating radial straight tube flow depends on the rotating speed and the entry flow problem requires future investigation. The secondary flow patterns were observed near the exit (1 $\mathrm{cm}$ upstream) of the test tube. The exit effect is considered to be negligible.

TABLE 1

Values of Experimental Parameters

\begin{tabular}{ll}
\hline Tube length-diameter ratio, $\ell / d$ & 21.52 \\
Tube-flow Reynolds number, Re & $0 \sim 4500$ \\
Rotation Reynolds number, $\mathrm{Re}_{\omega}$ & $0 \sim 1854$ \\
Rotation number, Ro & $0 \sim 1.236$ \\
Rotating speed, n, rpm & $25 \sim 200$ \\
\hline
\end{tabular}

In order to understand the effect of rotation, the values of rotation Reynolds number $\mathrm{Re}_{\omega}$ and rotation number Ro for different rotational speeds and Reynolds numbers are listed in Table 2 for reference. The present investigation should be regarded as basic study and the speed range represents the limitation of the experimental system.

\section{RESULTS AND DISCUSSION}

\section{Flow Phenomena Caused by Rotation in Radial- Axis Straight Tube}

For flow in a rotating radial straight tube, Coriolis accelerations cause secondary flow in the cross-sectional plane. Additionally, secondary flow and angular velocity also induce Coriolis forces in the direction of tube axis and the effect may be significant at large rotating speeds. Coriolis forces establish transverse pressure fields. As a result, a suction (low pressure) side exists near the leading side of the rotating cross-section and a high pressure side occurs near the trailing side. It is noted that the Coriolis forces act towards the trailing side of the rotating straight tube causing high pressure there.

TABLE 2

Values of $\operatorname{Re}_{\omega}$ and $\mathrm{Ro}$

\begin{tabular}{cccc}
\hline & $\operatorname{Re}_{\omega}$, & \multicolumn{2}{c}{$\mathrm{Ro}, \omega \mathrm{d} / \mathrm{u}_{\mathrm{m}}$} \\
$\mathrm{n}, \mathrm{rmp}$ & $\omega \mathrm{d}^{2} / \mathrm{v}$ & $\mathrm{Re}=1500$ & $\mathrm{Re}=4500$ \\
\hline 50 & 464 & 0.309 & 0.103 \\
100 & 927 & 0.618 & 0.206 \\
150 & 1391 & 0.927 & 0.309 \\
200 & 1854 & 1.236 & 0.412 \\
\hline
\end{tabular}


The flow field is a function of any two independent dimensionless groupings formed from the following three parameters:

Tube-flow Reynolds number, Rotation Reynolds number, Rotation number,

$$
\begin{aligned}
& \operatorname{Re}=u_{m} d / v \\
& \operatorname{Re}_{\omega}=\omega d^{2} / v \\
& \operatorname{Ro}=\omega d / u_{m}
\end{aligned}
$$

The reciprocal, $u_{m} / \omega d$, of the rotation number is known in the literature as the Rossby number. Ishigaki [1994] shows that an analogy exists between fully developed laminar flows in curved pipes and orthogonally rotating pipes using the parameter Dean number for curved pipes and $\operatorname{Re}(\operatorname{Ro})^{1 / 2}$ for rotating straight pipe flow using the values $\mathrm{Ro}=0.1$ and 0.01 for computation.

The basic regimes of tube flow are laminar and turbulent flows. Coriolis forces can have two different effects: (1) an effect on the early transition from laminar to turbulent flow, and (2) an effect on the relaminarization of turbulent flow or change of the structure of turbulence in the turbulent flow regime. The effect on the transition criterion may be either stabilizing (increasing the transition Reynolds number) or destabilizing (decreasing it), depending on the entrance Reynolds number, rotating speed and other entrance conditions.

Rotation has a stabilizing effect on the flow near the suction side of the tube and a destabilizing effect exists near the pressure side of the tube. If the flow is turbulent for zero rotation, the intensity of turbulence decreases as the rotation number increases. Transition from turbulent flow back to laminar flow occurs at higher values of rotation number. If the flow is laminar for zero rotation, transition from laminar to turbulent flow occurs at higher values of rotation number. The observations noted above can be verified by the secondary flow pattern.

The purpose of this paper is to study the flow transition phenomena described above by presenting flow visualization photographs. In this investigation, the rotating speed is $\mathrm{n} \leq 200 \mathrm{rpm}$ and the Reynolds number is in the range $\operatorname{Re} \leq 4500$.

\section{Secondary Flow Patterns for Stationary Case $(n=$ $0 \mathrm{rpm}$ ) with $\mathbf{R e}=\mathbf{5 0 0} \sim \mathbf{4 5 0 0}$}

The secondary flow patterns for stationary case $(n=0$ rpm) are shown in Fig. 3 for a range of Reynolds numbers $\operatorname{Re}=500 \sim 4500$ to see the effect of plenum box and the resulting 90-degree turn of the main flow. For each Reynolds number, several photos are shown to illustrate somewhat different features of flow patterns at different instants.

At $\operatorname{Re}=500$, a pair of vortices can be seen in the central region and a fluid layer exists near the circumference. The flow pattern is rather complex. At $\mathrm{Re}=$
1000 , a pair of vortices persists, but at $\operatorname{Re}=1500$ and 2000, two pairs of vortices appear. Multiple vortices occur for $\operatorname{Re}=2500 \sim 4500$. It will be seen later that these vortices caused by 90 -degree turn of the main flow disappear with rotation effects. The secondary flow patterns are seen to be very complex and no symmetry exists. Also, the flow is unsteady at higher Reynolds numbers. At higher Reynolds number $(\operatorname{Re}>2500)$, relaminarization process occurs due to secondary flow. For turbulent flow, smoke visualization fails due to smoke diffusion.

\section{Secondary Flow Patterns with Reynolds Number $\operatorname{Re}=1500$ and $n=25 \sim 189 \mathrm{rpm}$}

The secondary flow patterns for the case $\mathrm{Re}=1500$ and rotating speeds $n=25 \sim 189 \mathrm{rpm}$ are shown in Fig. 4 . For each rotating speed, several photos are shown to illustrate the nature of flow patterns at different instants. The number of frames presented for each rpm is arbitrary. In each photo, the left-hand side represents the leading side (suction side) and the right-hand side represents the trailing side (high pressure side). In Fig. 4 the change of rpm is denoted by the first appearance of rpm.

At $\mathrm{n}=25 \mathrm{rpm}$, a pair of counter-rotating vortices is clearly seen but the flow near the pressure side is somewhat different from that of the curved pipe flow with unstable region. The secondary flow near the leading side (low pressure) is quite regular and the flow separation can be seen. The dividing line between the upper and lower regions showing symmetry extends towards the center. The symmetry line is interrupted by the disturbances near the trailing side (high pressure). The boundary layer for secondary flow exists near the upper and lower walls.

At $\mathrm{n}=57 \mathrm{rpm}$, the streaming flow originating from the leading side is quite noticeable and the trend continues for $\mathrm{n}=86 \mathrm{rpm}$. The eyes of the vortices located near the leading side wall are clearly shown. One notices a triangular region near the trailing side and the secondary flow is seen to be somewhat irregular. The streaming flow near the leading side continues for $n=102$ and 123 $\mathrm{rpm}$. The region near the high pressure side is seen to be unstable. The transition from laminar to turbulent flow occurs near the high pressure side at $n=145 \mathrm{rpm}$. The disturbances are further amplified at $\mathrm{n}=172$ and 189 $\mathrm{rpm}$. At $\mathrm{Re}=1500$ the destabilizing effect of the Coriolis forces increases with the rotating speed and the early transition from laminar to turbulent flow occurs at $\mathrm{n}=$ $189 \mathrm{rpm}$. This is in sharp contrast with the stabilizing effects in curved pipe flows. At $\mathrm{n}=189 \mathrm{rpm}$, multiple 

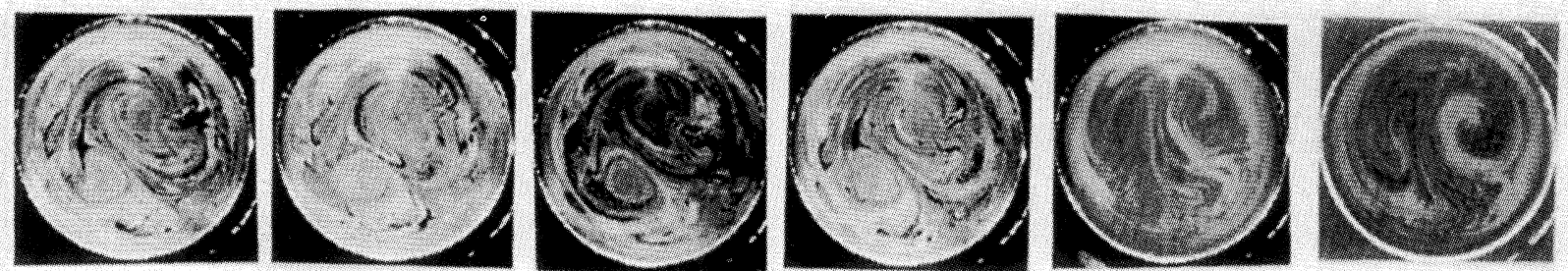

$\operatorname{Re}=500$

$\operatorname{Re}=1000$
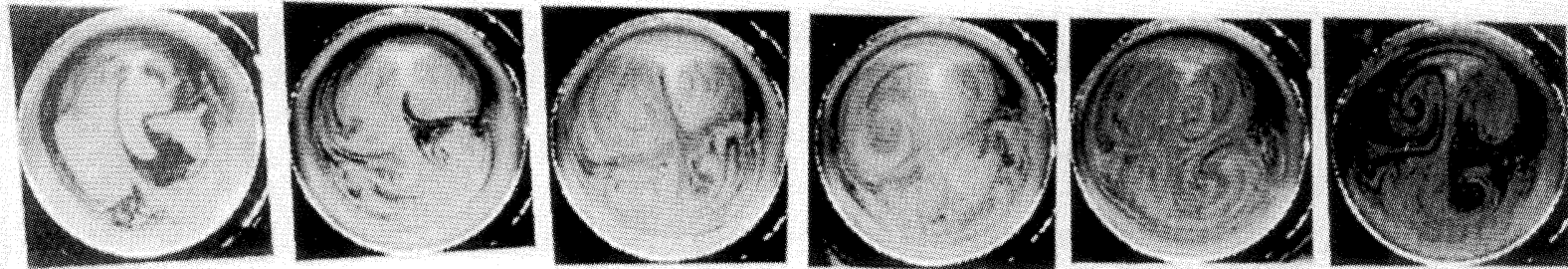

$\mathrm{Re}=1500$

$\operatorname{Re}=2000$
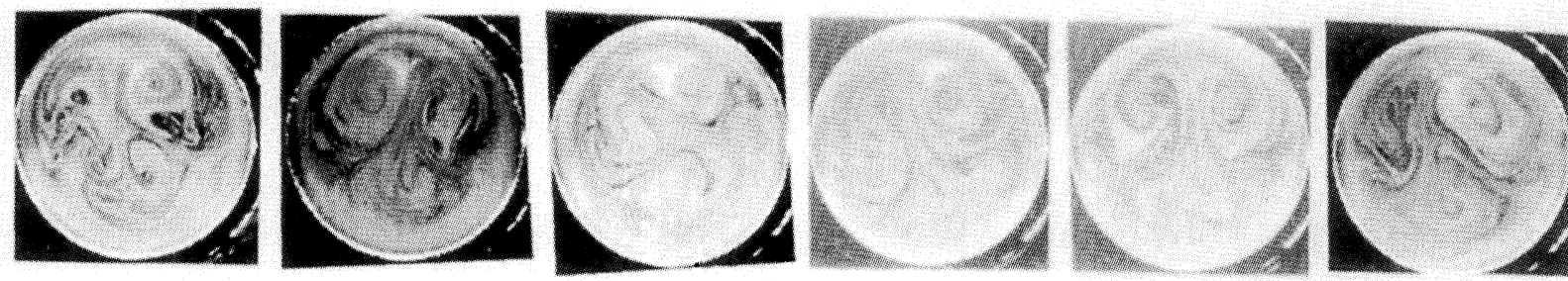

$\mathrm{Re}=2500$
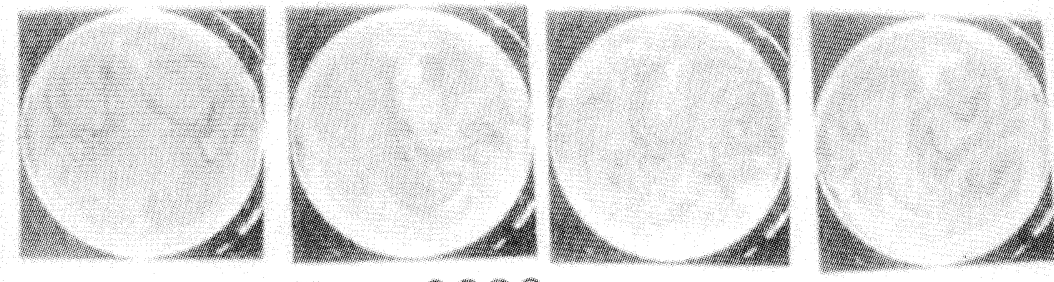

$\operatorname{Re}=3000$
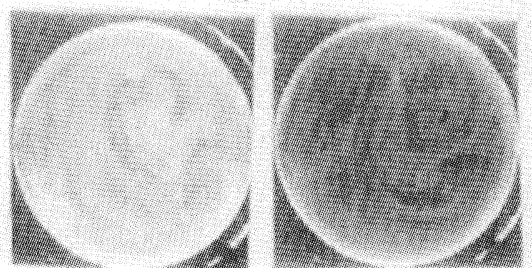

$\mathrm{Re}=3500$
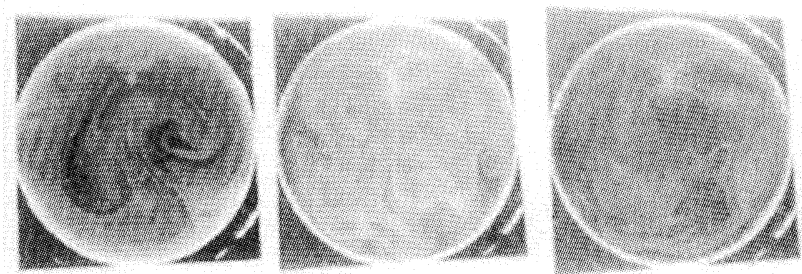

$\mathrm{Re}=4500$

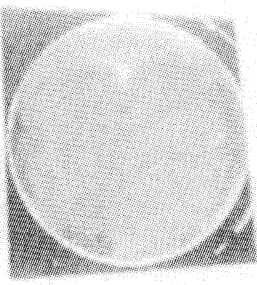

FIGURE 3 Secondary flow patterns at the pipe exit for stationary case $(\mathrm{n}=0 \mathrm{rpm})$ with $\operatorname{Re}=500 \sim 4500$ 


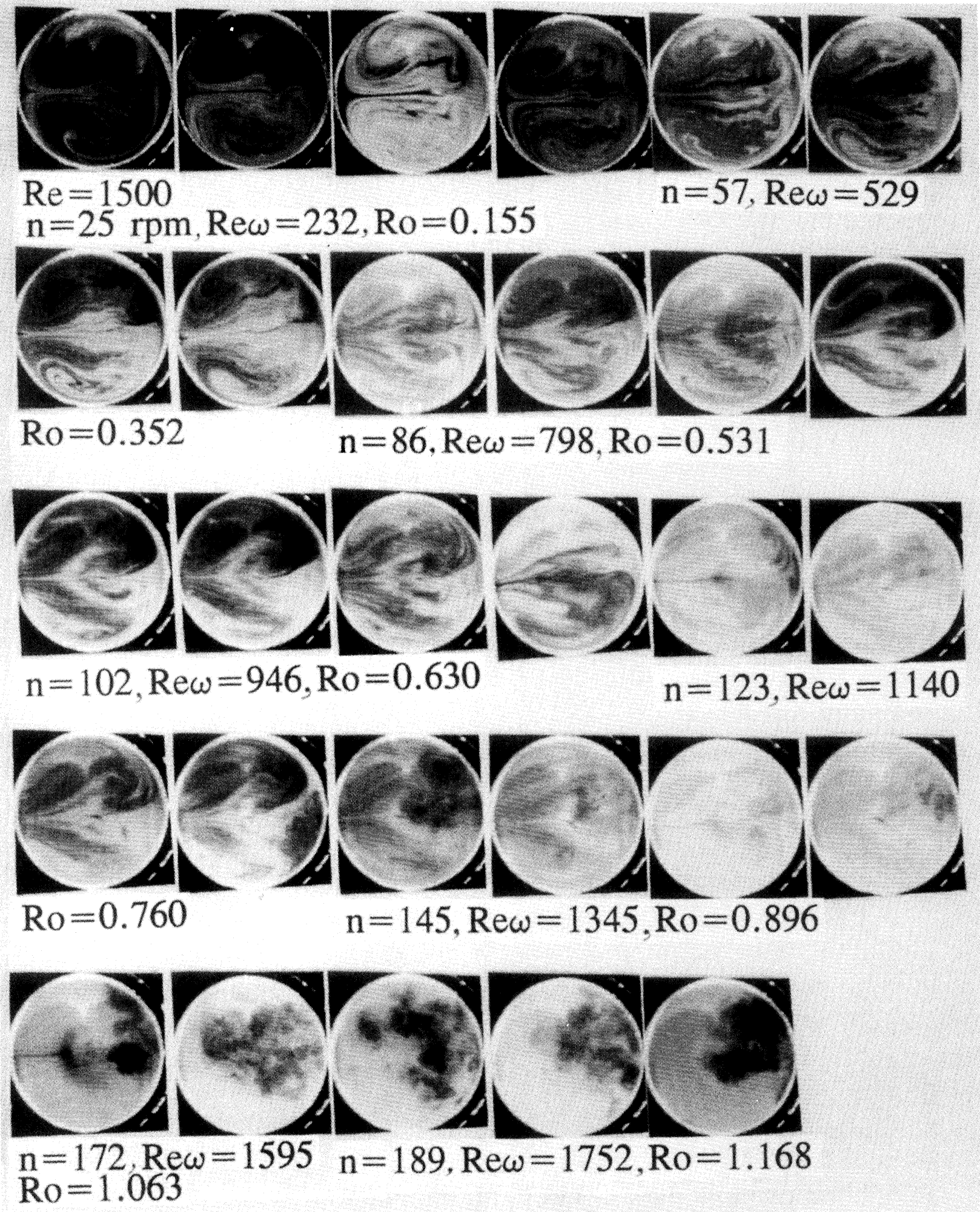


vortices appear near the high pressure side; the vortices become smaller and no symmetry of secondary flow exists. The visualization results show clearly that at higher rotation numbers the analogy between fully developed flows in curved pipes and in rotating straight tubes fails. The changing secondary flow patterns at $n=$ 172 and 189 rpm clearly reveal the transition regime. In Fig. 4 one observes the complete disappearance of the secondary flow patterns for the case without rotation (n $=0 \mathrm{rpm}$ ). One may conclude that the effect caused by the 90 degree bend of the main flow is negligible.

\section{Secondary Flow Patterns with $\operatorname{Re}=4500$ and $n=$ $36 \sim 200$ rpm, Fig. 5}

At $\operatorname{Re}=4500$, the flow in stationary straight pipe is in the turbulent regime. At lower rotating speed $n=36$ $\mathrm{rpm}$, the Coriolis effect is weak but the secondary flow near the leading side is clearly seen and the flow is laminar-like. In the remaining region, multiple vortices similar to those for the stationary case $(\mathrm{n}=0 \mathrm{rpm})$ can be seen.

At $\mathrm{n}=69 \mathrm{rpm}$, the secondary flow separation occurs near the leading wall and multiple vortices are seen near the trailing wall. The relaminarization process is apparently in progress.

At $n=73 \mathrm{rpm}$, a pair of counter-rotating vortices can be identified. The gradual relaminarization process near the leading wall is evident. The streaming flow from the leading wall towards the center starts at $\mathrm{n}=107 \mathrm{rpm}$ and the secondary flow near the trailing wall is quite irregular with no symmetry. The flow near the high pressure side is apparently unstable and the interaction between the upper and lower regions along the horizontal central axis is seen to be quite appreciable. The wavy dividing line near the center is of special interest.

At $\mathrm{n}=98 \mathrm{rpm}$, the first and second photos reveal the separation phenomenon near the leading wall but the remaining two photos show only the dividing line. The second photo for $\mathrm{n}=98 \mathrm{rpm}$ reveals multiple vortices clearly. Naturally it is rather difficult to draw definite conclusions with the constantly changing flow patterns.

At $\mathrm{n}=124 \mathrm{rpm}$, the stable streaming flow near the leading wall and the unstable irregular flow near the trailing wall are quite distinctive. The situation continues with further increase of the rotating speed at $n=150$, 163 and $178 \mathrm{rpm}$. The amplification of the disturbance in the region near the trailing wall is quite evident. In one photo at $\mathrm{n}=178 \mathrm{rpm}$, a pair of vortices appears near the trailing wall. At $n=200 \mathrm{rpm}$, the destabilizing effect near the trailing wall is seen to be dominant.
At $\operatorname{Re}=4500$, the relaminarization process depends on the rotating speed and it starts near the leading wall. A pair of vortices appears at lower rotating speed range $\mathrm{n}=36 \sim 107 \mathrm{rpm}$ revealing laminar-like flows. The effect of rotation on flow near the trailing wall is very complex and the flow is unsteady. The visualization photos for $\operatorname{Re}=4500$ reveal qualitative features of the complex relaminarization phenomena in rotating radial straight pipes caused by the stabilizing effects of the Coriolis forces. At $\operatorname{Re}=4500$, flow visualization would be impossible without secondary flow because of smoke diffusion in the turbulent regime; thus secondary flow patterns reveal the relaminarization process. At $\mathrm{Re}=$ 4500 the entrance effect due to the plenum box is seen to be rather small at $\mathrm{n}=36 \mathrm{rpm}$ and is negligible at higher rotating speeds.

\section{CONCLUDING REMARKS}

The flow visualization study clearly demonstrates that the Coriolis forces for flow in rotating radial straight pipes have both the destabilizing and stabilizing effects leading to the early transition from laminar to turbulent flow at $\operatorname{Re}=1500$ and relaminarization process at $\mathrm{Re}=$ 4500 , respectively. This is in sharp contrast to the stabilizing effects of centrifugal forces in curved pipe flows which delay the transition from laminar to turbulent flow.

In the literature (Ito and Nanbu [1971]) the transition from laminar to turbulent flow is usually inferred from the friction factors. Apparently the stabilizing and destabilizing phenomena revealed by the present investigation have not been studied in the past.

The effects of Coriolis forces on flow in rotating radial straight pipes have great implications for heating and cooling problems. The present investigation clarifies qualitatively the main features of the secondary phenomena caused by the destabilizing and stabilizing effects of the Coriolis forces in rotating radial pipe flows. The flow visualization results have practical implications for theoretical study. Apparently the flow visualization should be supplemented by measurements for flow fluctuations in future. Further insight can be obtained by comparing the present flow patterns with previous findings reported in the literature. The usual assumptions of symmetry and steady flow, and boundary approximation need revision.

\section{Acknowledgements}

This work was supported by the Natural Sciences and Engineering Research Council of Canada through an operating grant. 


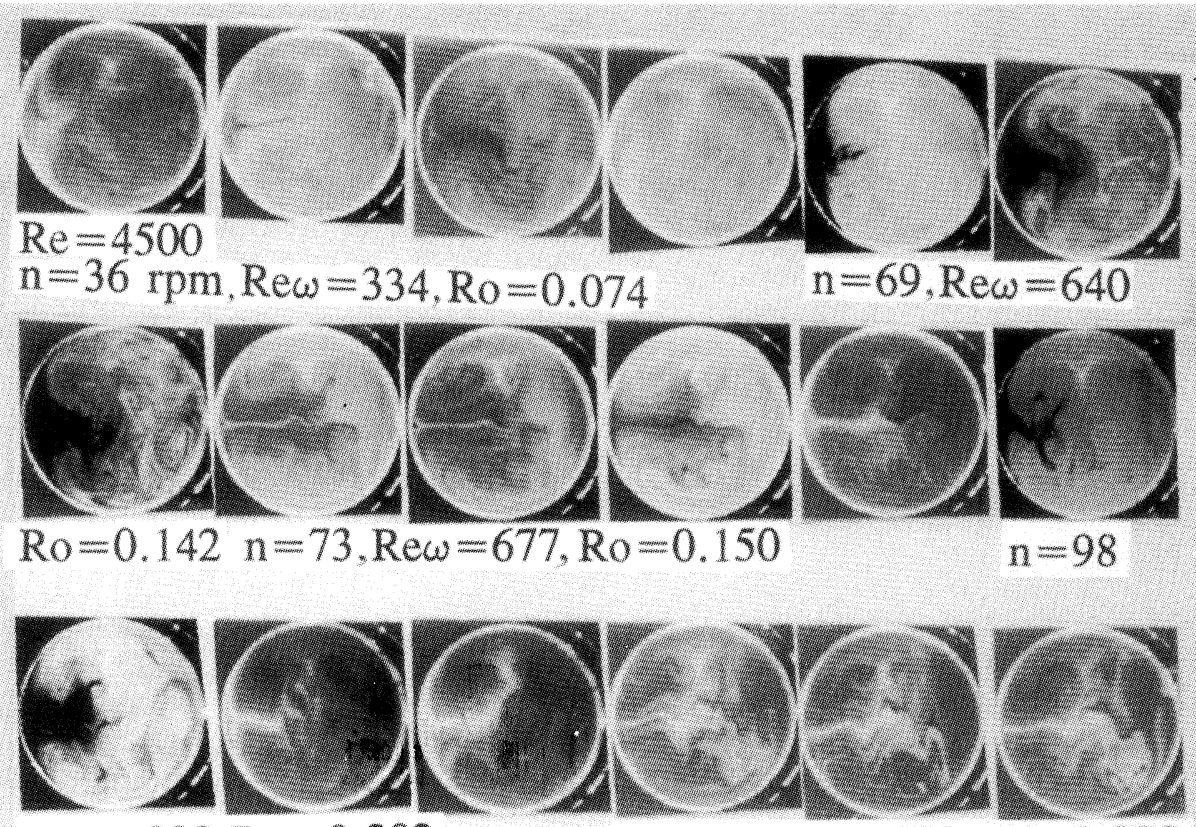

$\mathrm{Re}_{\omega}=908 . \mathrm{Ro}=0.202$

$n=107, \operatorname{Re} \omega=992, \operatorname{Ro}=0.220$
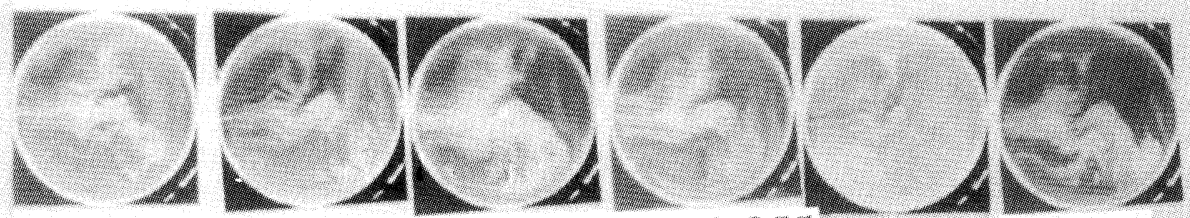

$\mathrm{n}=124 . \mathrm{Re} \omega=1149, \mathrm{Ro}=0.255$

$\mathrm{n}=150$
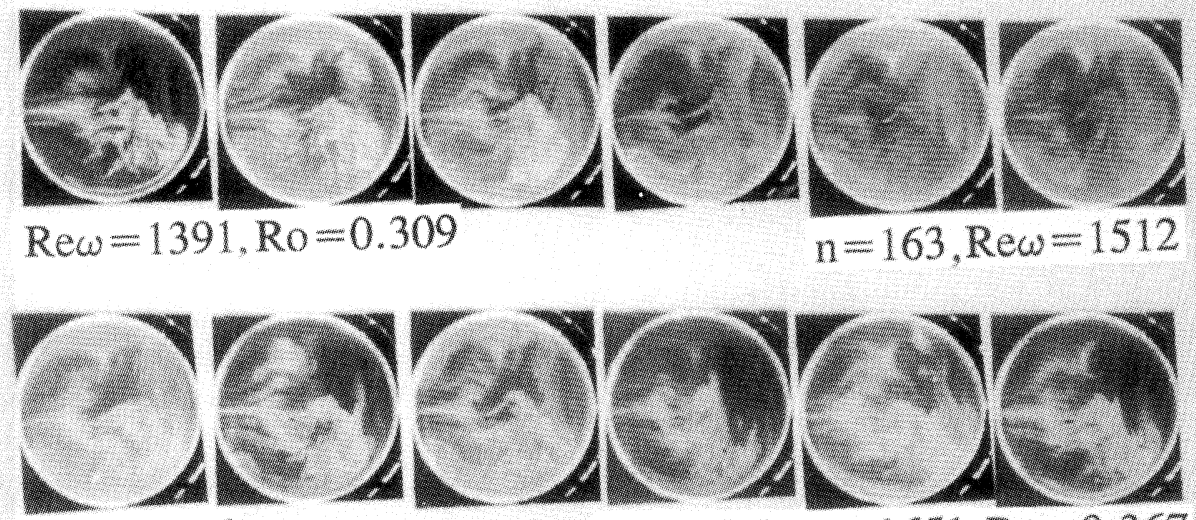

$\mathrm{Ro}=0.336$

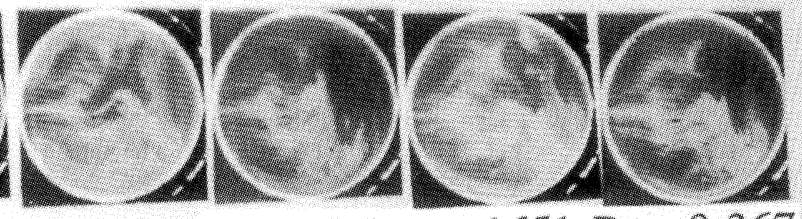

$n=178, \operatorname{Re} \omega=1651, \operatorname{Ro}=0.367$

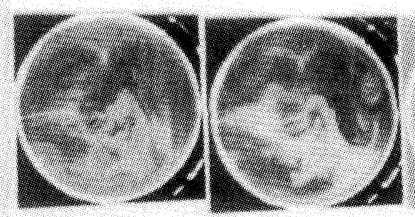

$$
n=200, \text { Re } \omega=1854, R_{0}=0.412
$$

FIGURE 5 Secondary flow patterns at the pipe exit for Reynolds number $\operatorname{Re}=4500$ and $\mathrm{n}=36 \sim 200 \mathrm{rpm}$. 


\section{Nomenclature}

$\begin{array}{ll}d & \text { tube inside diameter } \\ \ell & \text { tube length or entrance length } \\ n & \text { rotating speed, } \mathrm{rpm} \\ R e & \text { Reynolds number, } \mathrm{u}_{\mathrm{m}} \mathrm{d} / \mathrm{v} \\ R e_{\omega} & \text { rotation Reynolds number (Taylor number or } \\ & \text { reciprocal of Ekman number), } \omega \mathrm{d}^{2} / \nu \\ R o & \text { rotation number (reciprocal of } \operatorname{Rossby} \\ & \text { number), } \omega \mathrm{d} / \mathrm{u}_{\mathrm{m}} \\ u_{m} & \text { average axial velocity } \\ \nu & \text { kinematic viscosity } \\ \omega & \text { angular velocity }(2 \pi \mathrm{n} / 60)\end{array}$

\section{References}

Barua, S.N., 1974, Secondary Flow in a Rotating Straight Pipe, Proc. R. Soc. London, Vol. 227A, pp. 133-139.

Benton, G.S., 1956, The Effect of the Earth's Rotation on Laminar Flow in Pipes, ASME J. Appl. Mech., Vol. 23, pp. 123-127.

Benton, G.S. and Boyer, D., 1966, Flow Through a Rapidly Rotating Conduit of Arbitrary Cross-Section, J. Fluid Mech., Vol. 26, pp. 69-79.

Berman, J. and Mockros, L.F., 1984, Flow in a Rotating Non-Aligned Straight Pipe, J. Fluid Mech., Vol. 144, pp. 297-310.

Cheng, K.C. and Wang, L., 1993, Transition to Turbulence and Relaminarization Phenomena in Rotating Radial Straight Pipes,
HTD-Vol. 252, Visualization of Heat Transfer Processes, ASME, pp. 55-63.

Duck, P.W., 1983, Flow Through Rotating Straight Pipes of a Circular Cross Section, Phys. Fluids, Vol. 26, pp. 614-618.

Ishigaki, H. and Tamura, H., 1991, Laminar Flow in a Pipe Rotating around a Perpendicular Axis, Trans. JSME, Vol. 57B, pp. 2523-2529.

Ishigaki, H., 1994, Analogy Between Laminar Flows in Curved Pipes and Orthogonally Rotating Pipes, J. Fluid Mech., Vol. 268, pp. 133-145.

Ito, H. and Nanbu, K., 1971, Flow in Rotating Straight Pipes of Circular Cross-Section, ASME J. Basic Engineering, Vol. 93, pp. 383-394.

Ito, H., Hasegawa, S. and Yano, M., 1986, Laminar Flow through a Rotating Straight Pipe of Circular Cross Section, The Memoirs of the Institute of High speed Mechanics, Tohoku University, Japan, Vol. 56, No. 461, pp. 75-118.

Lei, U. and Hsu, C.H., 1990, Flow through Rotating Straight Pipes, Phys. Fluids A., Vol. 2, pp. 63-75.

Mansour, K., 1985, Laminar Flow through a Slowly Rotating Straight Pipe, J. Fluid Mech., Vol. 150, pp. 1-21.

Mori, Y., Fukada, T. and Nakayama, W., 1971, Convective Heat Transfer in a Rotating Radial Circular Pipe (2nd Report), Turbulent Region, Int. J. Heat Mass Transfer, Vol. 14, pp. 1807-1824.

Mori, Y. and Nakayama, W., 1968, Convective Heat Transfer in Rotating Radial Circular Pipes (1st Report, Laminar Region), Int. J. Heat Mass Transfer, Vol. 11, pp. 1027-1040.

Trefethen, L., 1957, Fluid Flow in Radial Rotating Tubes, Actes, 9ème Congr. Int. de Méc. Appl., Vol. 2, Université de Bruxelles, pp. $341-350$. 

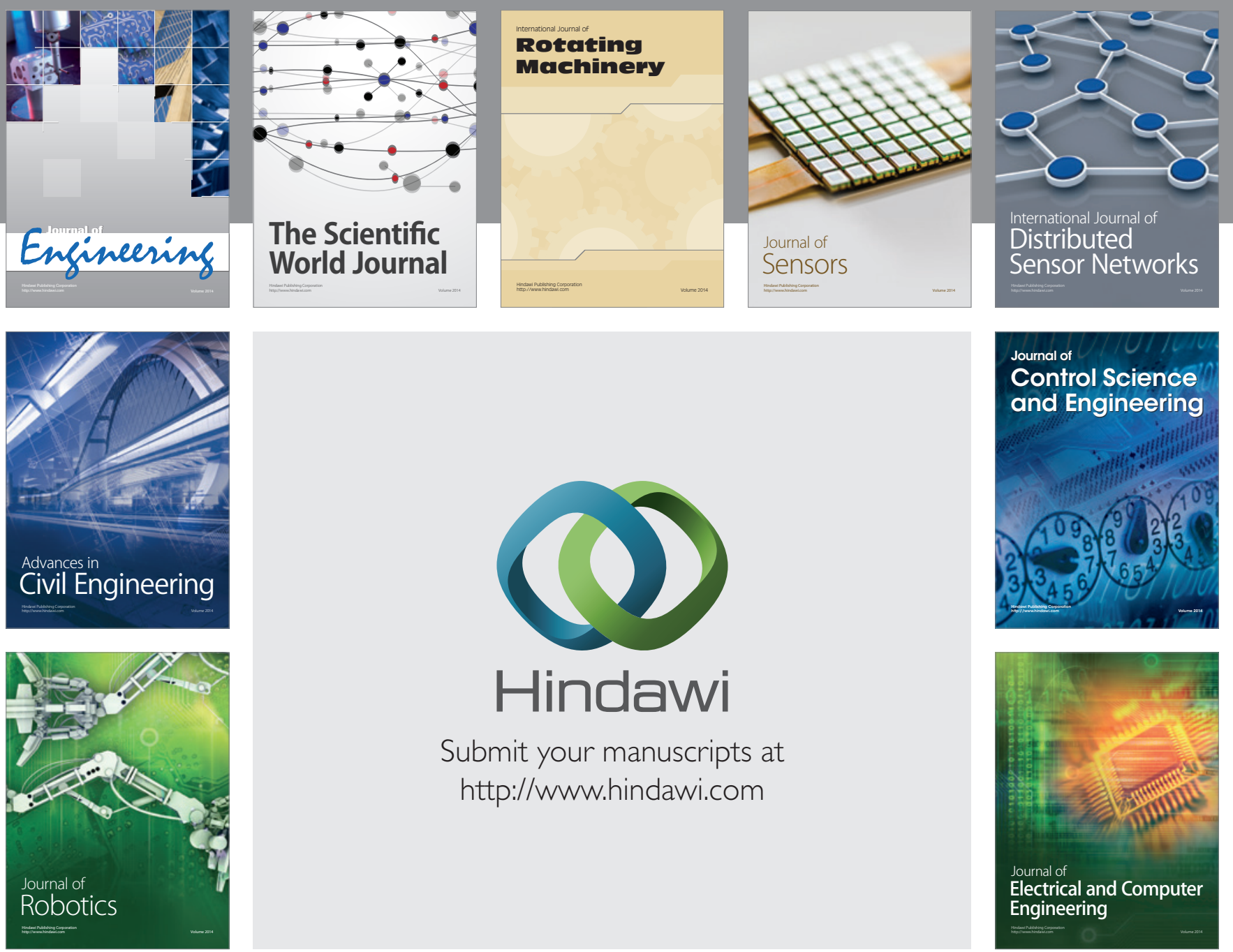

Submit your manuscripts at

http://www.hindawi.com
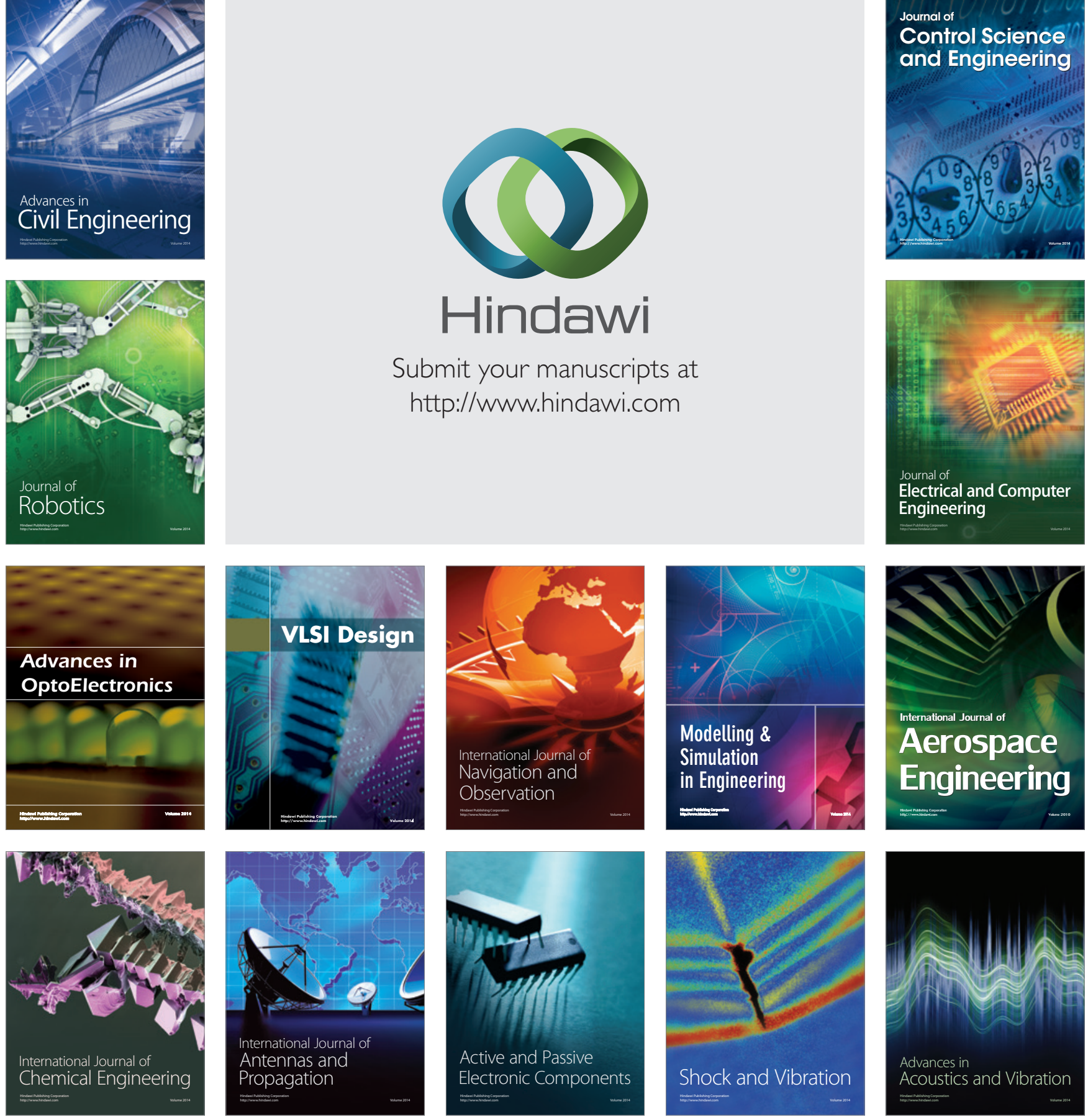